DOI 10.5216/ia.v46i3.63762

\title{
EDUCAÇÃO INFANTIL: HISTÓRICO E PERCEPÇÕES DE EDUCADORAS SOBRE A FUNÇÃO DA INSTITUIÇÃO
}

\author{
Caroline de Souza AraúJo \\ Universidade Estadual Paulista "Júlio de Mesquita Filho" (UNESP), Araraquara, São Paulo, \\ Brasil \\ Marcia Cristina Argenti Perez \\ Universidade Estadual Paulista "Júlio de Mesquita Filho" (UNESP), Araraquara, São Paulo, \\ Brasil
}

\begin{abstract}
Resumo: O objetivo deste artigo é apresentar um breve histórico da função da Educação Infantil e percepções de educadoras sobre similaridades entre creche e pré-escola e a função atual da instituição. A metodologia engloba pesquisas e documentos oficiais destinados à Educação Infantil e dados empíricos obtidos por observação participante e entrevista semiestruturada com oito educadoras de uma instituição municipal do interior de São Paulo. Os dados foram analisados com base no conceito de unidades significativas da Análise de Conteúdo de Bardin (2016). Os resultados mostram que o caráter assistencialista ainda se faz presente no interior das práticas educacionais, mas que avanços já foram alcançados no reconhecimento da criança e da função da instituição. Essa tem funções sociopolítica e pedagógica que devem ser cumpridas e reconhecidas.

Palavras-chave: Educação Infantil. Função da Instituição. Práticas Pedagógicas. Reconhecimento da Criança.
\end{abstract}

\section{INTRODUÇÃO}

A escola é uma das instituições responsáveis por introduzir os seres humanos na sociedade por meio da transmissão dos valores, costumes, práticas e cultura já existentes no ambiente social. Ao se apropriarem desses conteúdos culturais, histórica e humanamente produzidos ao longo do tempo, os seres humanos se tornam igualmente parte da sociedade em que convivem. Compreendendo que a escola tem essa responsabilidade em seu interior, subentende-se que, desde o início, deve-se proporcionar condições para que o indivíduo tenha acesso a esses conteúdos. Assim, a Educação Infantil deve também se preocupar com a garantia dessas condições e os educadores da instituição precisam se atentar em como fazer para que isso se concretize.

Explicita-se que essa preocupação deve estar presente desde o início da educação porque as instituições de Educação Infantil nem sempre se apresentaram da maneira que são hoje em dia, com a mesma forma de atendimento, englobando o mesmo público que abarca atualmente ou com a mesma função.

A Educação Infantil vem ganhando visibilidade no país, e assim, conquistando espaço para reflexões e investimento. Muitas lutas em torno dessa etapa da educação já 
foram vencidas, entretanto, não vieram facilmente, mas sim decorrente de uma história coletiva de militantes, intelectuais e movimentos sociais (KRAMER, 2006).

Essa instituição vem ganhando espaço para as discussões e reflexões, e assim surgem críticas sobre ela que aos poucos a melhoram. Essas críticas trazem consigo, de acordo com Kramer $(2006,2007)$, o fortalecimento da visão da criança como ser social, cidadã, que produz cultura, e que em seu interior são também produzidas por ela; além de intensificarem as lutas pelos direitos da educação das crianças atendidas pela Educação Infantil.

Frente aos avanços já conquistados, temos as Diretrizes Curriculares Nacionais para a Educação Infantil (DCNEI) apresentando esta etapa da educação como

Primeira etapa da educação básica, oferecida em creches e préescolas, às quais se caracterizam como espaços institucionais não domésticos que constituem estabelecimentos educacionais públicos ou privados que educam e cuidam de crianças de 0 a 5 anos de idade [...] É dever do Estado garantir a oferta de Educação Infantil pública, gratuita e de qualidade, sem requisito de seleção (BRASIL, 2010, p. 12).

Posto isso, consideramos importante explicitar a função da Educação Infantil como um todo, considerando ambas as partes que a compõem (creche e pré-escola), uma vez que ainda vemos, hoje em dia, a diferenciação de suas finalidades e a propagação de ideias que se faziam presentes no passado dessa instituição.

Sendo assim, buscamos por meio deste artigo trazer as discussões e reflexões realizadas por autores que versam sobre o assunto (KRAMER, 2006; KUHLMANN Jr., 2015; PEREZ, 2012; LOPES; MENDES; FARIA, 2006), além de apresentar e analisar as percepções de educadoras e pedagogas de uma instituição de Educação Infantil (0 a 5 anos) acerca da função da instituição, a fim de identificar se elas consideram que a creche e a préescola possuem diferenças ou semelhanças entre si.

\section{Metodologia}

A metodologia utilizada para a realização do presente trabalho conta com um estudo qualitativo fundamentado em pesquisas que abordam a Educação Infantil e documentos que se destinam à essa etapa da educação (BRASIL, 2010, 2017). Conta também com dados empíricos coletados em uma instituição municipal de Educação Infantil ( 0 a 5 anos) de uma cidade do interior do estado de São Paulo. Esses dados foram obtidos por meio de observação participante na referida instituição e entrevista semiestruturada com oito educadoras, sendo quatro delas da creche e quatro da pré-escola. A observação participante e a entrevista semiestruturada foram respaldadas pelos estudos de Severino (2007) e Lüdke e André (1986). A análise dos dados foi realizada segundo o conceito de categoria (unidades significativas) da Análise de Conteúdo de Bardin (2016).

A entrevista semiestruturada ocorreu com base em um roteiro elaborado previamente, apenas como norte da conversa. Esse roteiro apresentava as seguintes 
categorias: 1) Caracterização das educadoras; 2) Concepções da educação da criança na instituição de Educação Infantil; 3) Concepções da educação da criança na instituição familiar; e 4) Concepções sobre a relação escola-família. As categorias deste roteiro foram, posteriormente, classificadas também em subcategorias para a análise dos dados.

A categoria utilizada para a realização do presente artigo é intitulada Concepções da educação da criança na instituição de Educação Infantil e as subcategorias, aqui apresentadas, são intituladas Função da Educação Infantil e Semelhanças e diferenças entre creche e pré-escola.

\section{DESENVOLVIMENTO}

A Educação Infantil surgiu, inicialmente, com o intuito de cuidar e abrigar as crianças e retirá-las do ambiente que poderia contaminá-las, buscavam afastar as crianças da criminalidade por meio da escola (KUHLMANN JR., 2015). Nessa época, portanto, essa instituição apresentava um caráter puramente "assistencialista, higienista e até mesmo disciplinador da criança e de suas famílias" (LOPES, MENDES e FARIA, 2006).

A instituição não tinha o intuito de proporcionar à criança a criticidade e a emancipação através da educação, portanto sua qualidade de atendimento e educação eram baixas. $\mathrm{O}$ que se buscava por meio dessas, era meramente preparar a criança para a realidade que já lhe estava destinada, trazer conformidade.

Em seu início, não eram ofertadas a todas as crianças, destinavam-se apenas aos filhos e filhas das classes mais abastadas, ou em dado momento, apenas para abrigar as crianças dos trabalhadores.

Além disso, segundo a Base Nacional Comum Curricular (BNCC), a Educação Infantil era, até a década de 1980, mantida fora da educação básica, pois era considerada uma etapa de preparação para o Ensino Fundamental, que era considerada a etapa inicial da educação normal.

Lentamente, num processo de muitas lutas pelos direitos e educação das crianças de 0 a 6 anos, as instituições de Educação Infantil foram incorporando o caráter educacional, e, ademais, passou-se a considerar a assistência, a saúde e a educação como direito social de todas as crianças (KRAMER, 2006). Assim, com essas mudanças, em 1988, com a Constituição Federal, a Educação Infantil (creches e pré-escolas) tornaram-se responsabilidade do Estado para com as crianças de 0 a 6 anos. Mais adiante, em 1996, com o decreto da Lei de Diretrizes e Bases (LDB), essa etapa começou a ser considerada juntamente ao Ensino Fundamental e o Ensino Médio, como uma parte da educação básica. Em 2006 ocorreu uma alteração da LDB, de forma que a faixaetária a ser atendida pela Educação Infantil passou a corresponder às crianças de 0 a 5 anos. Essa mudança aconteceu somente pela antecipação do ingresso para o Ensino Fundamental.

Dessa forma, a Educação Infantil, desde 2006, compreende a primeira etapa da educação básica, sendo composta pela creche e pré-escola, de maneira que a primeira se dirige à oferta de educação para as crianças de 0 a 3 anos, e a segunda das crianças de 3 a 5 anos. Com todas essas mudanças no interior da instituição e suas funções, são constantes os processos de revisão das práticas ocorridas e das concepções de educação para crianças, buscando manter a instituição com objetivos que se concretizem em si própria, ou seja, que tenha objetivos relacionados àquela própria etapa da educação e 
não prevendo a solução de problemas de outras etapas. As Diretrizes Curriculares Nacionais para a Educação Infantil (DCNEI) explicitam essa afirmação no seguinte excerto:

[...] o campo da Educação Infantil vive um intenso processo de revisão de concepções sobre educação de crianças em espaços coletivos, e de seleção e fortalecimento de práticas pedagógicas mediadoras de aprendizagens e do desenvolvimento das crianças. Em especial, têm se mostrado prioritárias as discussões sobre como orientar o trabalho junto às crianças de até três anos em creches e como assegurar práticas junto às crianças de quatro e cinco anos que prevejam formas de garantir a continuidade no processo de aprendizagem e desenvolvimento das crianças, sem antecipação de conteúdos que serão trabalhados no Ensino Fundamental (BRASIL, 2010, p. 7).

O que se percebe também é que o documento traz em si a questão do ensino dentro da instituição e da importância do reconhecimento do papel do professor para que essas práticas pedagógicas se concretizem de maneira adequada. Sendo assim, o que se compreende como objetivo de ambas (creche e pré-escola) é o cuidar e o educar. Entretanto, é importante ressaltar que não é necessário que se busque atribuir culpa ao assistencialismo quando se afirma que a função da Educação Infantil é também ensinar, afinal, segundo Kuhlmann Jr. (2015), ambas andam juntas no interior dessa instituição, uma vez que toda atividade compreende algum tipo de educação, assim como é imprescindível que se cuide das crianças dessa faixa-etária.

Indo ao encontro disso, a BNCC explica que, nessa etapa, o cuidar e o educar são indissociáveis e que, ao incorporá-los em sua proposta pedagógica, as instituições de Educação Infantil devem se comprometer com o objetivo de ampliar as experiências, conhecimentos e habilidades das crianças, sempre trazendo em suas práticas a continuidade com as aprendizagens recebidas no ambiente familiar. $O$ documento também enfatiza que as práticas devem acontecer por meio de interações e brincadeiras, ressaltando também que essas interações devem ser tanto com outras crianças quanto com adultos, pois isso proporcionará oportunidades de construírem e se apropriarem dos conhecimentos já existentes na sociedade.

Essa afirmação colocada pela BNCC vai ao encontro da ideia de que a escola proporciona para a criança o seu desenvolvimento nos mais amplos aspectos:

A criança, na escola, amplia seus interesses além do mundo infantil e dos objetos, estende as possibilidades de relações sociais, estabelece interações mais diversificadas com os adultos, compreende, paulatinamente, as atitudes e as várias formas de atividades humanas: trabalho, lazer, produção cultural e científica (PEREZ, 2012, p. 20).

Além disso, se vincula também à importante concepção apresentada por Perez (2012), de que as brincadeiras são fundamentais para o processo de aprendizagem da 
ARAÚJO, C. de S.; PEREZ, M. C. A.

criança desta faixa-etária, trazendo influências significativas tanto em sua personalidade infantil como em sua formação psíquica.

A BNCC ainda traz em si a importância da intencionalidade educativa e da mediação do professor na Educação Infantil, e explica que é imprescindível que o educador reflita sobre quais ações serão capazes de promover o desenvolvimento da criança e como devem trabalhar para que ele se efetive. Fica claro, portanto, que os educadores dessas instituições devem refletir a respeito de suas práticas a todo instante: antes de trabalhá-la, durante o processo educativo e após tê-las trabalhado. Esse processo de reflexão após a atividade é importante porque, por meio dos resultados, o educador pode dizer se essa foi significativa ou não.

Ademais, para confirmar as funções a serem desempenhadas pela Educação Infantil, trazemos o que se apresenta nas DCNEI como objetivos das propostas pedagógicas dessas instituições.

A proposta pedagógica das instituições de Educação Infantil deve ter como objetivo garantir à criança acesso a processos de apropriação, renovação e articulação de conhecimentos e aprendizagens de diferentes linguagens, assim como o direito à proteção, à saúde, à liberdade, à confiança, ao respeito, à dignidade, à brincadeira, à convivência e à interação com outras crianças (BRASIL, 2010, p. 18).

As DCNEl afirmam que é dever das instituições garantir o cumprimento de sua função sociopolítica e pedagógica, oferecendo às crianças, dessa forma, condições e recursos para que desfrutem de seus direitos civis, humanos e sociais; se responsabilizando por compartilhar e complementar a educação e cuidado advindos das famílias; possibilitando interações entre adultos e crianças para que seus conhecimentos e saberes se ampliem; promovendo iguais oportunidades educacionais para as crianças das mais diferentes classes sociais e construindo novas formas de sociabilidade e subjetividade que sejam pautadas nos mais amplos aspectos sociais (BRASIL, 2010).

Com essa apresentação das funções da Educação Infantil, consideramos importante identificar as percepções de educadoras sobre quais elas pensam que sejam as funções dessa instituição, a fim de analisar se suas concepções alinham-se à real função. Foram entrevistadas oito educadoras, sendo que quatro delas são da creche e as outras quatro da pré-escola. Serão atribuídos nomes fictícios a cada uma delas para que a identificação das concepções se tornem mais claras ao leitor.

\section{CARACTERIZAÇÃO DAS EDUCADORAS}

Para maior facilidade e compreensão na leitura, utilizaremos nomes fictícios para nos referirmos às entrevistadas. Passaremos a nos referir, portanto, às educadoras da creche como Marta, Roberta, Simone e Juliana.

A educadora Marta tem 63 anos, é formada até o Ensino Médio e trabalha como agente educacional há 28 anos; a educadora Roberta tem 53 anos e, assim como Marta, é formada até o Ensino Médio, estando a trabalhar como agente educacional há 14 anos; Educadora Simone tem 50 anos, é formada em Licenciatura em Ciências Biológicas e 
trabalha como agente educacional há 26 anos; por fim, a Educadora Juliana tem 27 anos, é formada em Pedagogia e trabalha como agente educacional há 5 anos.

Denominaremos as educadoras referentes à pré-escola como Educadora Bárbara, Educadora Camila, Educadora Josiane e Educadora Natália. A Educadora Bárbara tem 55 anos, é formada pelo magistério e atua como professora substituta na Educação Infantil há 7 anos; Educadora Camila tem 52 anos, é formada em Pedagogia e possui pós-graduação em Psicopedagogia e trabalha como professora há 26 anos; Educadora Josiane tem 47 anos, é também formada em Pedagogia e possui pósgraduação em Psicopedagogia e atua como professora há 20 anos; e a Educadora Natália tem 35 anos, é graduada em Pedagogia e atua como professora há 10 anos.

\section{SOBRE A FUNÇÃO DA INSTITUIÇÃO DE EDUCAÇÃO INFANTIL}

Quando questionamos as educadoras sobre qual elas entendem que seja a função da instituição, percebemos clara a ideia por parte de todas elas de que a função principal da Educação Infantil é de cuidar e educar as crianças, entendendo que eles são indissociáveis. Algumas educadoras como a Educadora Marta, Educadora Simone e Educadora Natália mostraram que compreendem que essa instituição deve ensinar e estimular a criança e seu desenvolvimento em seus mais amplos aspectos, indo ao encontro do que foi acima trazido dos documentos destinados à essa instituição (Brasil, 2010, 2017).

Todas as educadoras dão ênfase também ao fato de que a Educação Infantil é também uma escola, parte da educação básica e que, portanto, tem função pedagógica, função de ensinar às crianças tudo aquilo que elas podem aprender, uma vez que são seres completamente capazes de aprender. Elas enfatizam também o quanto é importante que haja continuidade entre o que a criança aprende na família e o que aprende na escola, para que assim seu desenvolvimento aconteça com mais facilidade. A fala da Educadora Simone dá destaque a essas concepções:

A função da creche é complementar a educação da família, porque é uma escola, não deixa de ser uma escola, tem o desenvolvimento né enquanto escola, e também enquanto educação mesmo, o desenvolvimento da criança em todos os aspectos assim de emocional, criatividade... é, trabalhar com o desenvolvimento da criança amplamente. (Trecho retirado da entrevista com a Educadora Simone, 51 anos, 2018).

Por meio dessa colocação da Educadora Simone, percebemos a compreensão de que a escola se trata de um local que promove um conhecimento sistematizado, mas que deve ser contínuo com o que é desenvolvido na família. Percebe-se a compreensão de algo fundamental quando tratamos sobre a Educação Infantil, a percepção de que a continuidade deve existir, mas que as práticas educativas realizadas dentro de cada ambiente se dão de maneiras diferentes, uma vez que as exercidas na família apresentam, de acordo com Perez (2009), resultados rápidos no comportamento do educando, enquanto que na escola, a transmissão engloba uma preparação para a 
realidade futura da criança, além de envolver momentos programados, sendo previamente preparados por pessoas específicas como professores, grupo de sala de aula e funcionários.

Apesar de demonstrarem a compreensão da existência do ensino dentro dessa instituição, chamamos atenção para a fala da Educadora Roberta, que considera que não pode exercer o ensino dentro da instituição por não ser formada em Pedagogia: "...com meus exemplos e ensino eu to educando. Então não é só o cuidar, eu to educando, é a parte pedagógica... não que parte pedagógica é com as professoras" (Trecho retirado da entrevista com a Educadora Roberta, 53 anos, 2018). Isso nos mostra que ela considera que o ensino dentro das instituições deve ser realizado por pessoas específicas, entendendo que é necessária uma preparação para lidar com crianças pequenas, o que nos possibilita enxergar também que se faz presente, até nos dias atuais, a desvalorização da Educação Infantil, pois acredita-se que não é necessária formação para se trabalhar com crianças pequenas.

Além disso, notamos também presentes em algumas falas das educadoras da creche quando as questionamos sobre a função da instituição, a forte presença do caráter assistencialista. Elas citam a ideia do ensino, porém seus exemplos se destinam majoritariamente às questões relacionadas aos cuidados essenciais das crianças. Isso nos confirma que dentro das instituições de Educação Infantil ainda existem muitas práticas baseadas em uma perspectiva meramente assistencialista (LOPES; MENDES; FARIA, 2006).

\section{SOBRE AS SEMELHANÇAS E DIFERENÇAS ENTRE CRECHE E PRÉ-ESCOLA}

Notando esse caráter assistencial e a percepção de algumas educadoras da creche sobre a necessidade de ter formação para que se possa exercer o caráter educativo da instituição, tomamos a decisão de questionar as educadoras da pré-escola sobre o que pensam acerca das semelhanças e as diferenças entre a creche e a préescola.

Por meio dessa pergunta, pudemos perceber uma divisão entre as professoras que ainda possuem a ideia de que a creche corresponde ao caráter assistencial enquanto a pré-escola se destina ao ensino, e algumas que compreendem a instituição de Educação Infantil como um todo, considerando que essa etapa, assim como o Ensino Fundamental e Médio, compõe a educação básica, e, portanto, não enxergam diferenças entre elas, ou apontam que, apesar de perceberem que existem diferenças, consideram que elas não deveriam existir.

Para a Educadora Josiane, ambas são diferentes, e afirma que: "A creche é assistencialismo, a pré-escola é... a gente trabalha todos os conteúdos que trabalham no fundamental só que de forma diferente, de uma forma lúdica, uma forma mais suave, mas trabalhando todos os conceitos né" (Trecho retirado da entrevista com a Educadora Josiane, 47 anos, 2018). Essa fala da professora apresenta alguns equívocos, como por exemplo, a concepção de que a creche corresponde ao assistencialismo, pois fortalece a ideia de que esta etapa tem a mera função de cuidar das crianças e suprir suas necessidades básicas. Além disso, traz consigo a ideia de que a pré-escola tem como função adiantar os conteúdos do Ensino Fundamental, o que é o oposto do que é afirmado nas DCNEl: 
Na transição para o Ensino Fundamental a proposta pedagógica deve prever formas para garantir a continuidade no processo de aprendizagem e desenvolvimento das crianças, respeitando as especificidades etárias, sem antecipação de conteúdos que serão trabalhados no Ensino Fundamental (BRASIL, 2010, p. 30).

A Educadora Bárbara, assim como a Educadora Josiane, traz a ideia de que a creche se caracteriza pelo assistencialismo, pois afirma que não enxerga a instituição como creche, uma vez que em "nenhuma das idades você tem o trabalho somente de cuidador, de cuidar da criança, você tá sempre trabalhando no desenvolvimento integral da criança" (Trecho retirado da entrevista com a Educadora Bárbara, 55 anos, 2018). Nessa fala, a educadora mostra que compreende que em toda faixa-etária a criança aprende e se desenvolve, porém, inicialmente, aponta que não enxerga a instituição como creche, atribuindo a esta o trabalho unicamente de cuidados.

A Educadora Camila destaca a única diferença que percebe entre a creche e a pré-escola, enfatizando que em sua concepção, deveria acontecer de maneira diferente:

Acredito que a semelhança das duas é que trabalha com uma faixaetária de criança, a faixa-etária principal onde eles aprendem mais, onde eles absorvem mais. $\mathrm{E}$ a diferença... olha, pra mim não tem nenhuma, mas vou falar uma que... eu acredito que é a formação dos profissionais que trabalham na creche. Eu acredito que teria que ser tudo professor, desde o berçário (Trecho retirado da entrevista com a Educadora Camila, 52 anos, 2018).

Essa afirmação da professora se destaca, pois se aproxima dos argumentos da Educadora Roberta a respeito de não poder exercer a função de educar por não ser formada em Pedagogia. A fala de Camila, bem como a de Roberta, nos mostra o quanto é importante que a função do pedagogo seja reconhecida, desde as etapas mais iniciais da Educação Infantil. Isso nos traz, ainda, a importante reflexão que Tardif (2009) apresenta, de que é perceptível o quanto é necessário que o educador tenha formação específica, uma vez que seu trabalho está baseado em conceitos complexos, que refletem suas posturas nas mais diferentes situações com as quais podem se deparar.

Vemos, portanto, que desde os níveis iniciais da educação, o educador vai se encontrar em diferentes situações com as quais terá que lidar, e deverá assumir determinadas posturas, a fim de proporcionar à criança condições de aprendizagem e desenvolvimento, para isso ele deve ter o conhecimento adequado para executar suas práticas.

Assim como Educadora Camila, a Educadora Natália afirma que não pensa que deveria existir diferença entre ambas as etapas e ressalta que não acredita que deveria haver essa divisão na Educação Infantil:

Na realidade, não era pra ter diferença nenhuma. Eles entendem que a creche é o cuidar né, e a pré-escola é a instrução né, instruir, ensinar. Eu acredito que a criança, ela aprende desde que ela nasce né, ela tá aprendendo com os pais, ela aprende no berçário, então 
ARAÚJO, C. de S.; PEREZ, M. C. A.

se você, é igual Vigotski fala, se você conseguir proporcionar esse desenvolvimento através da mediação, através de objetos que você pode estar aí auxiliando esse desenvolvimento, desde o berçário, olha o quanto que a criança vai se desenvolver até ela chegar na $5^{\mathrm{a}}$ etapa né, então a gente não pode perder os processos né, sempre estar auxiliando a criança desde o berçário até a pré-escola. Eu não gosto dessa divisão, eu acho que a Educação Infantil é do berçário até a $5^{\text {a }}$ etapa, mas eles gostam de dividir né, de 0 a 3 anos creche e de 3 a 5 anos pré-escola (Trecho retirado da entrevista com a Educadora Natália, 35 anos, 2018).

Essa fala da professora é importante, pois percebe-se que ela leva em consideração não só que a creche e a pré-escola são um todo, compondo a Educação Infantil, como também entende que, nessa etapa, é necessária a mediação para que o desenvolvimento pleno da criança aconteça. Além disso, percebe que a criança aprende a todo momento, desde muito pequena e das relações informais com o conhecimento, e que, por essa razão, tudo na escola deve ser ensinado.

\section{CONSIDERAÇÕES FINAIS}

Concluímos, portanto, que a Educação Infantil, engloba a creche e a pré-escola e, dessa forma, se compõe como um todo, sendo assim, sua função é nas duas áreas a mesma. A função da Educação Infantil, afirmada nas DCNEl e na BNCC (Brasil, 2010, 2017) é de proporcionar às crianças de 0 a 5 anos o cuidado e o ensino, respeitando suas singularidades, promovendo atividades que tenham sentido e significado e sejam executadas por meio de brincadeiras, que nesta faixa-etária são a forma mais efetiva de aprendizagem, sempre com a mediação do adulto e percebemos que as educadoras têm essa mesma concepção, ou seja, compreendem qual é a função da instituição de Educação Infantil, reconhecendo-a como um todo (creche e pré-escola) que deve proporcionar os cuidados básicos e também as questões de desenvolvimento cognitivo que demandam as crianças dessa faixa-etária.

Percebemos que, apesar de ter conseguido alguns avanços ao longo dos anos, ainda falta à instituição de Educação Infantil o seu reconhecimento de seu caráter pedagógico e o reconhecimento da importância do pedagogo em todas as suas etapas (creche e pré-escola) e isso torna-se claro também pelas falas das próprias educadoras, que apesar de mostrarem compreender que a instituição tem caráter pedagógico, ainda se atêm muito ao caráter assistencial e reconhecem o quanto é importante ter propriedade sobre determinados conhecimentos para exercer a profissão.

As educadoras concebem que o cuidar e o educar estão presentes em ambas as etapas e são indissociáveis e necessários para o desenvolvimento da criança dessa faixaetária, assim como é afirmado nos estudos e documentos que versam sobre a Educação Infantil. Percebemos o quanto é fundamental que os educadores e professores dessa instituição sejam valorizados e reconhecidos por seu trabalho, sendo contratados de acordo com sua formação, uma vez que as próprias educadoras demonstram mais segurança para agir quando possuem formação ou quando são orientadas por quem tem formação na área. Seria importante também que as instituições oferecessem formação continuada aos professores para que constantemente aperfeiçoassem suas 
práticas e concepções sobre a função da instituição e do público com o qual trabalha, e sua própria função.

Artigo recebido em: 04/06/2020

Aprovado para publicação em: 14/12/2021

\section{CHILDHOOD EDUCATION: HISTORY AND PERCEPTIONS OF EDUCATORS ABOUT THE INSTITUTION'S ROLE}

ABSTRACT: This article aims to present a brief history about the Childhood Education's role and the perceptions of educators about the similarities between nursery school and preschool, and the institution's actual role. The methodology includes studies and official documents that are intended to the Childhood Education and empirical data obtained through participant observation and semistructured interview with eight educators from a county's institution of Sao Paulo's state. The data were analyzed based on the concept of significant units of Bardin's Content Analysis (2016). The results show that the welfare character is still present inside the educational practices, but that advances were already achieved on the child's recognition and the institution's role. The institution has socio-political and pedagogical functions that must be fulfilled and recognized.

KEYWORDS: Childhood Education. Intitution's Role. Pedagogical Practices. Child's Recognition.

EDUCACIÓN INFANTIL: HISTORIA Y PERCEPCIONES DE EDUCADORES SOBRE LA FUNCIÓN DE LA INSTITUICIÓN

RESUMEN: Este artículo tiene como objetivo presentar un breve histórico de la función de Educación Infantil y percepciones de educadores sobre similitudes de la guardería y el preescolar, y el papel actual de la instituición. La metodología incluye investigaciones y documentos dirigidos a la Educación Infantil y datos empíricos obtenidos por observación participante y entrevistas semiestructuradas con ocho educadores de una instituición municipal del interior de São Paulo. Los datos se analizaron según el concepto de unidades significativas del Análisis de Contenido de Bardin (2016). Resultados muestran que el carácter asistencial está presente en las prácticas educativas, pero se han logrado avances en el reconocimiento del niño y del papel de la instituición. Sus funciones sociopolítica y pedagógica deben de ser cumplidas y reconocidas.

PALABRAS-CLAVE: Educación Infantil. Papel de la Instituición. Prácticas Pedagógicas. Reconocimiento del Niño. 
ARAÚJO, C. de S.; PEREZ, M. C. A.

REFERÊNCIAS

BARDIN, L. Análise de conteúdo. São Paulo: Edições 70, 2016.

BRASIL. Ministério da Educação. Base Nacional Comum Curricular. Brasília: MEC, 2017.

BRASIL. Ministério da Educação. Secretaria de Educação Básica. Diretrizes Curriculares Nacionais para a Educação Infantil/Secretaria de Educação Básica -Brasília: MEC, SEB, 2010.

KRAMER, S. A infância e sua singularidade.In: Ministério da Educação. Secretaria de Educação Básica. Ensino Fundamental de nove anos: orientações para a inclusão da criança de seis anos de idade. 2. ed. Brasília: MEC, SEB, 2007, p. 13 - 23.

KRAMER, S. As crianças de 0 a 6 anos nas políticas educacionais no Brasil: Educação Infantil e/é Fundamental. Educ. soc., Campinas, vol. 27, n. 96 -Especial, p. 797 -818, out. 2006.

KUHLMANN JR., M. Infância e Educação Infantil: uma abordagem histórica.7. Ed. Porto Alegre: Mediação, 2015.

LOPES, K. R.; MENDES, R. P.; FARIA, V. L. B. (org.). Coleção Proinfantil.Módulo III, unidade 2, livro de estudo -volume2.Brasília: MEC.Secretaria de Educação Básica.Secretaria de Educação à Distância, 2006.

LÜDKE, M. Pesquisa em educação: abordagens qualitativas/ Menga Lüdke, Marli E. D. A. André. - São Paulo: EPU, 1986.

PEREZ, M. C. A. Família e escola na contemporaneidade: fenômeno social. Revista Ibero-Americana de Estudos em Educação, v. 4, n. 3, 2009, p. 1 - 16.

PEREZ, M. C. A.Infância e escolarização: Discutindo a relação família, escola e as especificidades da infância na escola.Práxis Educacional, Vitória da Conquista, v.8, n.12, p. $11-25$, jan./jun. 2012.

SEVERINO, A. J. Metodologia do trabalho científico.23a ed. São Paulo: Cortez, 2007.

TARDIF, M. O trabalho docente hoje: elementos para um quadro de análise. In: TARDIF, M. O trabalho docente: elementos para uma teoria da docência como profissão de interações humanas / Maurice Tardif, Claude Lessard; tradução de João Batista Kreuch. 5. ed. - Petrópolis, Rio de Janeiro: Vozes, 2009, p. 15 - 54.

Caroline de Souza Araújo: Graduada em Pedagogia (2021) pela Universidade Estadual Paulista Júlio de Mesquita Filho, UNESP - Faculdade de Ciências e Letras, 
Campus de Araraquara. Mestranda em Educação Escolar (2021) na Universidade Estadual Paulista Júlio de Mesquita Filho, UNESP - Faculdade de Ciências e Letras, Campus de Araraquara. Atua na área de Educação como professora de inglês em escola de idiomas.

Orcid: https://orcid.org/0000-0002-1485-3157

E-mail: carolined_@hotmail.com

Marcia Cristina Argenti Perez: Doutora em Psicologia (Ciências) pelo Programa de Pós-graduação em Psicologia da Universidade de São Paulo (USP, 2004), Mestra em Psicologia pela Universidade de São Paulo (USP, 2000) e Pedagoga com habilitação em Deficiência Intelectual pela Universidade Estadual Paulista (UNESP, 1997). Atualmente é Chefe, Docente e Pesquisadora do Departamento de Psicologia da Educação da Faculdade de Ciências e Letras, UNESP, Campus de Araraquara, SP. Docente dos Programas de Pós-Graduação em Educação Escolar (Acadêmico) e Educação Sexual (Profissional) da UNESP - FCLAr.

Orcid: https://orcid. org/0000-0002-4173-9923

E-mail: marcia.argent@unesp.br

Este periódico utiliza a licença Creative Commons Attribution 3.0, para periódicos de acesso aberto (Open Archives Initiative - OAI). 